\title{
Evaluating the Environmental Performance of 3D Printed Shelters in Jordan
}

\author{
"Mohanad Akeila', Christopher Preece ${ }^{2}$ and Kelvin Kuok King Kuok'
}

\begin{abstract}
First submission: 11 February 2020; Accepted: 28 October 2020; Published: 8 December 2021
To cite this article: Mohanad Akeila, Christopher Preece and Kelvin Kuok King Kuok (2021). Evaluating the environmental performance of 3D printed shelters in Jordan. Journal of Construction in Developing Countries, 26(2): 117-134. https://doi.org/10.21315/jcdc2021.26.2.6
\end{abstract}

To link to this article: https://doi.org/10.21315/jcdc2021.26.2.6

\begin{abstract}
Three-dimensional (3D) printed shelters are an innovative housing solution for those in need of a shelter after a disaster. The Middle East generated a huge number of refugees due to internal conflicts. The technology has been investigated earlier from a cost and time perspectives and has performed better than steel shelters in Jordan. This research article investigates environmental performance of 3D printed shelters in Jordan in terms of energy, fuel, cooling and ventilation. Syrian refugees of Jordanian camps were selected as a case study. The energy simulation of the steel shelter to that of a printed shelter showed that the latter can achieve higher ventilation rates, lower energy consumption, less electricity cost and better thermal insulation than steel shelters.
\end{abstract}

Keywords: 3D printed shelters, Environmental performance, Energy simulation, Syrian refugees

\section{INTRODUCTION}

The immigration wave, resulting from internal conflicts following the Arab spring, generated millions of refugees being displaced all over the region. According to the United Nations, the Middle East refugees account for more than $13 \%$ of the global refugees (UNHCR [United Nations High Commissioner for Refugees], 2018). These refugees were supported by local and global aid organisations who support refugee camps with millions of dollars to provide them with food and other items. Nonfood items such as shelters, clothes, bedding and household items consume a large amount of energy to be delivered and operated at the location of aid. Recent technologies are emerging in the refugee sheltering environment to enhance the daily life of inhabitants and promote refugee knowledge on today's innovative tools. Cash cards, laser cutting and foldable shelters are the result of engineering and technology initiatives to support refugees around the globe (UNHCR Greece, 2017). Technologies adopted in humanitarian fields imposed a positive influence on the place of location. For example, the printed pipe section in a Nepal camp restored the water network function at short notice (Field Ready, 2014). Some technologies such as three-dimensional (3D) printing, however, are still in its early stage of integration to the humanitarian environment. A previous article by Akeila, Kuok and Wong (2019) provided the cost efficiency of 3D printed shelters over steel transitional

\footnotetext{
'Faculty of Engineering, Computing and Science, Swinburne University of Technology Sarawak Campus, Kuching, Sarawak, MALAYSIA

${ }^{2}$ College of Engineering, Abu Dhabi University, Abu Dhabi, UNITED ARAB EMIRATES

*Corresponding author: mrmohanad1@hotmail.com
} 
shelters in Jordan. This article will investigate the environmental performance of advanced design model to promote energy performance of 3D printed shelters in comparison to steel shelters in Jordan.

\section{LITERATURE REVIEW}

Multiple types of shelters have been constructed in Jordan over the past decade to enhance the living qualities of Syrian refugees; however, the Jordanian shelters miss the durability, stability and thermal comfort of the occupants. The latest innovative shelters constructed by UNHCR using steel interlocking framing system cladded by thermal panels and corrugated sheets have enhanced the thermal comfort of occupants to certain limits. An advanced type of shelter can enhance the thermal comfort of refugees and reduce the consumption of natural resources deployed to construct the shelter. Therefore, this research article will investigate the energy performances of the steel shelter and will introduce printable counterparts as an alternative and better performing option on measured performances such as energy, ventilation, fuel, electricity and mechanical cooling.

\section{Shelter Environmental Performance}

Environmental performance of a shelter is built on the standards that need to be implemented in the design model to ensure adequacy to climate conditions and refugee comfort. The first performance is the thermal insulation of the shelter which is the main factor of controlling the inner temperate of individual rooms. The second performance is the acoustic insulation, which is the amount of sound walls that reflect to reduce the inner noise. Ventilation, on the other hand, is the relation between the pressure of the air intake through the openings (windows and door) to the atmospheric pressure. Proper ventilation will reduce the amount of energy consumption needed to run an air conditioner or a fan in order to circulate the air located at the footstep of the shelter to higher levels of breathing. The following four elements will be used in the comparison of the environmental performance of steel shelter to 3D printed shelters.

\section{Thermal insulation}

The thermal performance of building structure is ranked on the insulation it can achieve against sun radiation, air temperature and radiation temperature and interior air humidity. The radiation projected by the sun can be resisted by roof material that achieves $900 \mathrm{kWh} / \mathrm{m}^{2} \mathrm{a}$ to $1,150 \mathrm{kWh} / \mathrm{m}^{2} \mathrm{a}$ of sun radiation. Glare produced by the sun can control the amount of natural light passing to the shelter. The artificial day light at night shall be minimised to 300 lux. The optimum conformance level of the artificial light varies from 50 lux to 300 lux (Aburamadan, 2017). 
Heat radiation generated during the hot dry climate shall be resisted by shade that would reduce the shelter surrounding temperature. The shaded outer area shall achieve a maximum temperature of $26^{\circ} \mathrm{C}$ to avoid overheating of shelter walls, which increases the impact of energy consumption to cool the occupied area of the shelter (Richarz and Schulz, 2013).

Air humidity is the source of dis-conformance in countries having a coastal line with the sea such as the southern side of Jordan, where the humidity can reach to $45 \%$ (WorldData.info, 2019). Shelters with humidity ratio of $40 \%$ to $60 \%$ can reduce the dust accumulation inside the shelter. The water vapour ratio in the air is less in areas located away from the sea. Thus, in Mafraq, Jordan (the current spot of Syrian refugee), humidity vary $4 \%$ to $15 \%$ over the year (Weather Spark, 2019).

\section{Acoustic comfort}

Acoustic insulation is the amount of sound prevention a wall provides to in-house occupants. Hotel residency promotes a high level of sound insulation through filling the walls and ceiling with sound proofing materials such as Eco-polipiombo, mineral fibres and hollow bricks. A combination of sound proofing material can achieve $69 \mathrm{~dB}$; however, floor mats provides sound proofing of $40 \mathrm{~dB}$ to $75 \mathrm{~dB}$ (Département $\mathrm{Tl}, 2007$ ). In smaller shelters with an area of $35 \mathrm{~m}^{2}$ to $48 \mathrm{~m}^{2}$ that are built by concrete and masonry walls, the sound levels range $18 \mathrm{~dB}$ to $26 \mathrm{~dB}$ (Ritchie and Thomas, 2013).

\section{Energy consumption control}

Energy conservation is a concept in project construction that controls project resources from a conservative perspective. Efficient energy consumption can be determined by the amount of resources saved during a construction life cycle. For example, rain water can be harvested through polyvinyl chloride (PVC) or copper pipes toward plastic barrels. The harvested water can be either purified for public use or can be utilised for irrigation. Major slope should be considered in the designing of the shelter roof for rain harvesting to avoid collecting water at the roof.

Water pipes that connect washing basin taps, showers and toilet valves shall be in the same type of context/materials. The reason behind this is to reduce the amount of chemical reaction resulting from using different water pipes that could contaminate the water.

Electricity to Syrian refugees in Zataari camp is generated by a solar plant funded by the Czech Republic. The solar plant came in response to the high consumption of electricity by refugees. The KfW $12.9 \mathrm{MW}$ solar plant was completed in October 2017 and was considered to be the largest renewable infrastructure in a refugee camp in the world. The average electricity consumption per household was recorded to $66 \mathrm{kWh}$ per year, which is equal to the daily consumption of $2.2 \mathrm{kWh}$ per day (Dupin, 2018). 


\section{Ventilation}

The amount of air circulation within a housing unit is measured by the ventilation ratio of each window provided over the day. Ventilation ratio contributes to air quality within the shelter premises by minimising smells and gases. The comfortable ratio for indoor air quality that prevents bad smells and gases ranges between $0.7 \mathrm{dp}$ and $2.5 \mathrm{dp}$ (Fuchs, Hegger and Stark, 2013). Decipol (dp) is a measuring unit for perceived air quality within the space of sensory load for one standard person ventilated by $10 \mathrm{~L} / \mathrm{s}$ (Fanger, 1988; Wikipedia, 2018).

Ventilation can promote good air circulation if the window is placed in a high position of the walls. However, the light access would not be controlled; therefore, a window positioned at $1.2 \mathrm{~m}$ from the shelter ground level will enhance the inside air quality. The ventilation through the shelter can be maximised with the window in the roof. However, cost obligation should be properly considered prior to adding windows for ventilation and increasing the oxygen level in case of minimum ventilation ratio and oxygen levels $\left(1.8 \mathrm{~m}^{3} / \mathrm{h}\right)$ are attained (Hegger et al., 2012)

\section{Transitional Shelters in Jordan}

The steel shelters in Jordan are designed and executed by the UNHCR to house the Syrian refugees. The shelters were used excessively in Azraq camp; as a matter of fact, more than 65,000 refugees were accommodated in 13,000 T-shelters. The T-shelter is made of an interlocking steel structure cladded by aluminum foam insulation (15 mm thick) and are covered by a double layer of corrugated inverted box rib (IBR) sheet $(0.35 \mathrm{~mm}$ thick each) (UNCHR, 2016). Figure 1 presents the steel transitional cladding layers.

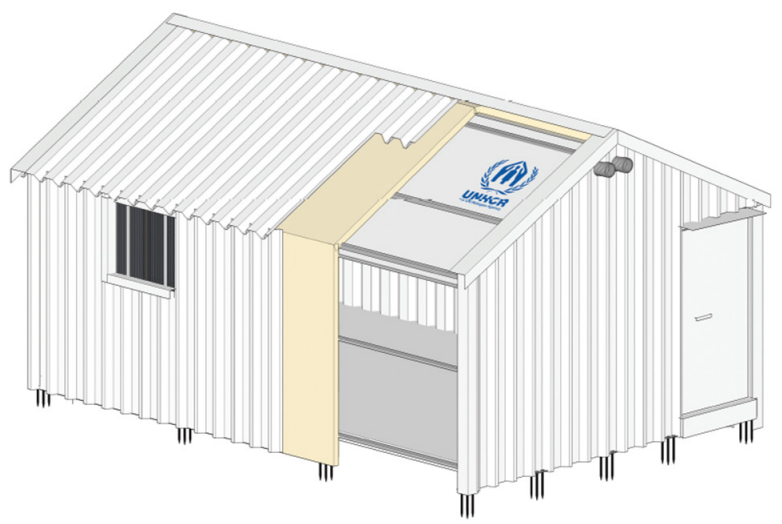

Figure 1. T-shelter cladded by aluminium foam insulation between two IBR sheets Source: UNHCR (2015)

The vertical steel tubes of the interlocking structure are fitted with an adjustable steel footing that can be fixed at three heights to reduce the alignment time. The steel footing is made of steel plate fixed to the ground by four pigs, as shown in Figures 2 and 3. 


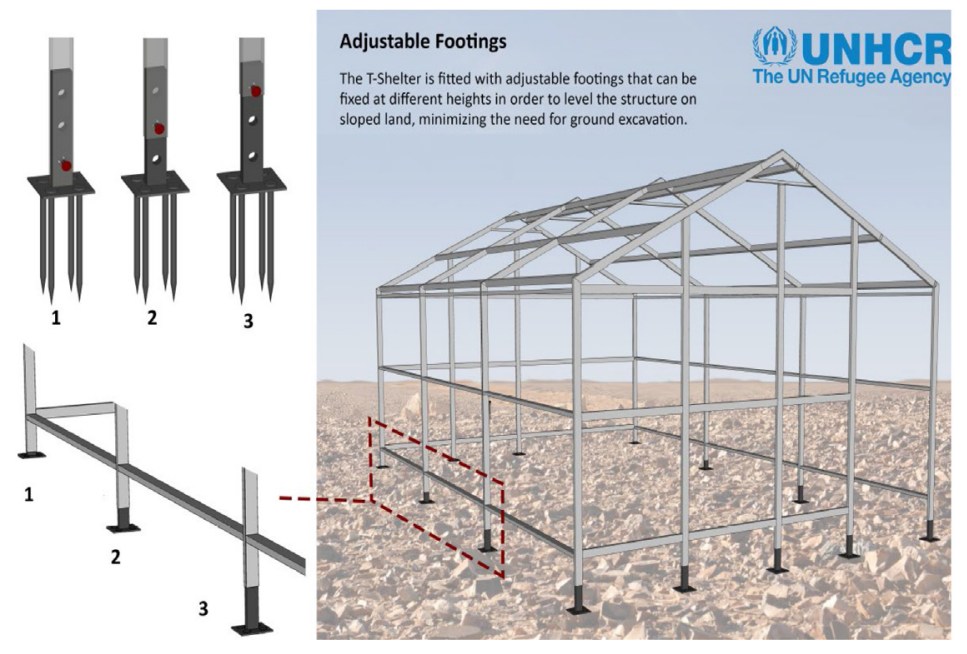

Figure 2. Transitional shelter steel structure with adjustable footings Source: UNHCR (2015)

Upon the completion of the interlock system and footing alignment, a concrete foundation $(30 \mathrm{~cm} \times 30 \mathrm{~cm} \times 30 \mathrm{~cm}$ ) is to be casted on the base plate to stabilise the steel plate beneath and work as a receiving structure to reinforced concrete slab above it. The reinforced slab forms the shelter flooring, which is made of $5 \mathrm{~cm}$-reinforced concrete with $6 \mathrm{~mm}$ steel rebar placed at $30 \mathrm{~cm}$ spacing (UNCHR, 2016).

The steel components, such as the steel tubes of the interlock system, are delivered to the site in a form of kit to ease the transportation and installation process. The shelter design is fixable enough to accommodate side doors to enhance the privacy of occupants.

\section{Methodology: Environmental Analysis through BIM Platform}

Building information modelling (BIM) is an integration of several software into a single platform in order to deliver a final product model. BIM models developed in the platform can control the architectural, structural, environmental, cost, time and facility management of the building (Duell, Hathorn and Hathorn, 2015). This research focused on the integration between BIM platform and 3D printed structures from the environmental performance perspective. The following two cloud based tools from the BIM family analysed the environmental performance of designed models prior to construction that gives the designer a better understanding on model energy, thermal, solar, acoustic and carbon dioxide $\left(\mathrm{CO}_{2}\right)$ performances. The cloud-based tools will be used after the complete design and configuration of the thermal settings in the models in order to generate the environmental performances of the shelters. The simulation results will be compared in order to define the efficiency of printed shelter over the steel shelter using improvement value formula. 


\section{Green Building Studio}

This cloud-based energy analysis service is available for architects, engineers and building analysts who want to build and improve energy performances on new and existing buildings. The service allows the design to perform whole building energy analysis to understand energy use and carbon footprint applications of building designs. Green Building Studio uses information from energy analysis for Autodesk Revit as the foundation for engineering-driven calculations by linking design models. The service also supports the import of Green Building XML (gbXML) format from other Autodesk or third-party solution. The platform can view, iterate and test the performance of multiple design options as an intargeted part of the design workflow. The platform can test different building orientations and increase the thermal resistance of walls without creating different design models within the design software. Green Building Studio delivers easy-to-understand graphical results that help in forming design decisions. The potential energy saving chart can help the design team and also align how to improve energy performance of projects as well as help communicate building performance to project stakeholders and building owners. Green Building Studio helps improve the quality of the design through whole building energy, water and carbon analysis by leveraging the cloud computing capacity offered in Autodesk 360. This service helps the designer to analyse designs more rapidly than ever before, allowing the exploration of more alternatives. Finally, Autodesk Green Buildings Studio enables the designer to optimise energy efficiency and work towards carbon neutrality early in the design process (Autodesk, 2011).

\section{Autodesk Insight 360}

BIM work can be maximised through insight, which is a powerful cloud-based analysis tool in the architecture, engineering and construction (AEC) collection. Insight helps to improve energy and environmental performance throughout the building life cycle, by energy analysis, lighting analysis and solar analysis for holistic approach to building performance design. Environmental-friendly design decisions are now possible using insight cloud-based analysis tools to iterate and optimise project parameters during the design stage. Insight is capable of creating automatic energy models from refit concept to detail design. The cloud-based software allows access to analyse and visualise modelling environment. Insight can visualise and interact with key performance indicators, factors, ranges and specification through real-time cost and affect feedback. Insight quantifies and visualises heating and cooling loads and performs sun and shadow studies to accurately see how lighting conditions affect designed model. Insight also simulates day lighting and glare as well as calculates the solar photovoltaic (PV) within design environment. The cloud-based environmental analysis tool can present multiple inter-related aspects of building performance parameters before construction. Insight extends the capabilities and value with Autodesk AEC collection through unprecedentedly levels of cloud-based performance analysis (Autodesk, 2016). 


\section{D Printing in Building Shelters}

A previous article entitled "Evaluating the Visibility of Building Syrian Refugee Shelters by 3D Printing Technology in Jordan" presents the potential of the technology in saving the construction cost over transitional steel shelter located in Jordan for refugees. The 3D printable model presented in the article followed the traditional 3D designs, which are made of zigzag printed wall. The model presented in the article was made of cast in situ foundation within 3D printed frame and walls, along with precast concrete roof. The wall was composed of double layers of $5 \mathrm{~cm}$ concrete connected by $5 \mathrm{~cm}$ zigzag printed concrete. The overall size of the shelter was $36 \mathrm{~m}^{2}$ and was specious enough to accommodate two rooms, a kitchen and bathroom. The isometric Figure 4 presents the 3D printed shelter from our previous article (Akeila, Kuok and Wong, 2019).

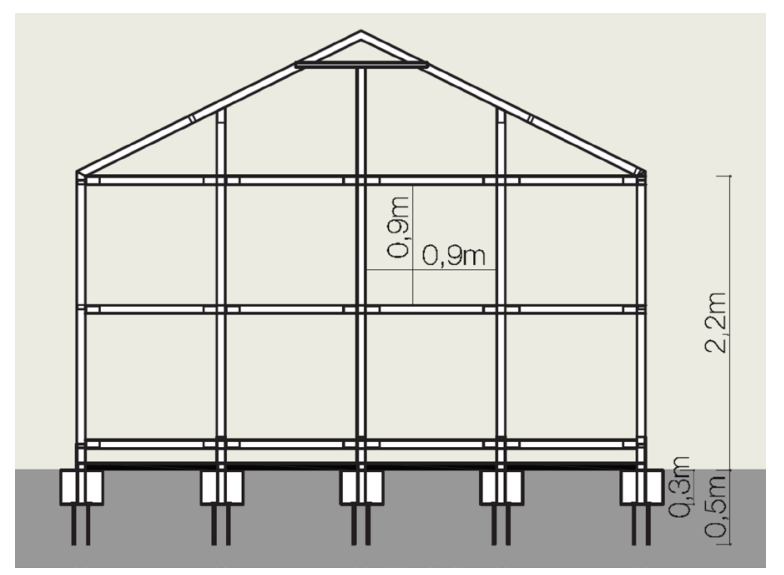

Figure 3. Cross-section of T-shelter present connection between the steel tubes, concrete slab and footings Source: UNCHR (2016)

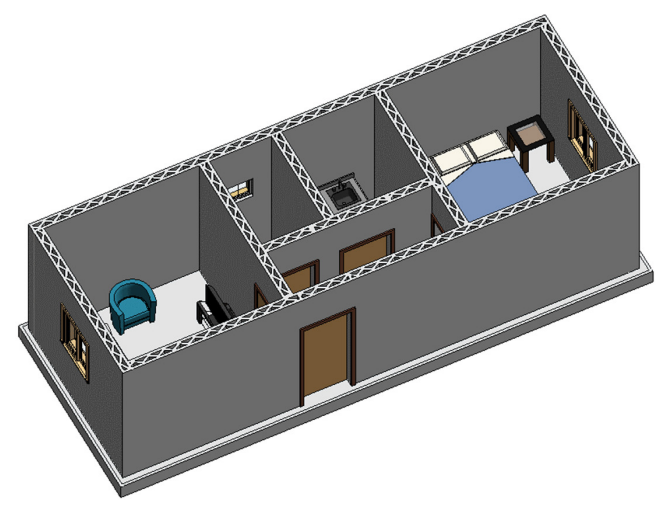

Figure 4. 3D printed shelter Source: Akeila, Kuok and Wong (2019) 


\section{COMPARING ENVIRONMENTAL PERFORMANCE OF STEEL SHELTER TO 3D PRINTED SHELTERS}

The developed model of the printed shelter from the previous article achieved $6 \%$ cost saving over steel ones even through the sizes of both were not equivalent. This article will introduce one model with two construction materials (steel and 3D printed concrete) to identify which shelter can achieve the environmental requirements illustrated in the literature review as well as perform better than the other in terms of thermal and acoustic insulation, energy and fuel consumption, along with enhancement of ventilation.

\section{Enhanced 3D Printed Shelter Model}

The shelter foundation made up of C30 concrete was casted within a mould of 3D printed frame made of $5 \mathrm{~cm}$ concrete. The thickness of the foundation was $30 \mathrm{~cm}$ to stand the combination of load as well as stop water ingress in the event of floods. The walls to be printed were of $3 \mathrm{~m}$ height and connected by using a rectangular box of size $10 \mathrm{~cm} \times 10 \mathrm{~cm}$ to avoid using the zigzag printed profile. The walls were made of a double unit system, which is $5 \mathrm{~cm}$ outer wall, $10 \mathrm{~cm}$ air gap and $5 \mathrm{~cm}$ inner wall. The following figure 5 summarises the development of the printable shelter in steps. The first step of printing the shelter was to print the frame of the foundation and entrance step. The second step of cast was within the printed frame ordinary Portland cement (OPC) concrete. The third step was printing the walls. Forth step connected the walls by concrete columns. The concrete columns frame was printed similar to the foundation frame and then filled with OPC concrete. The final step was anchoring the steel roof tubes to the concrete columns in order to pin the roof sandwich panel to the steel tubes.
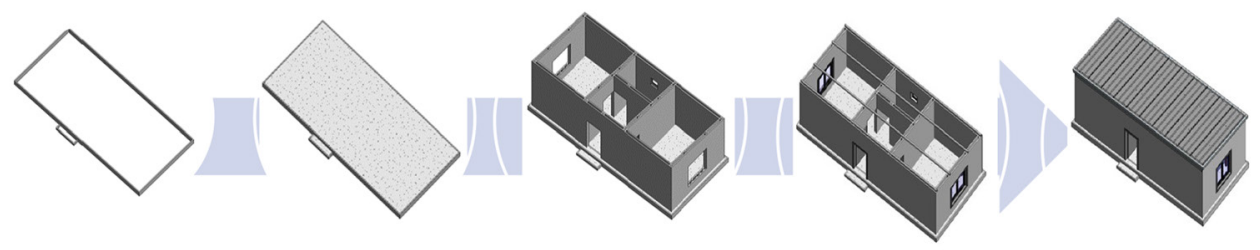

Figure 5. 3D Printed shelter design stages

The printed wall can stand still under this design as the structural analysis is simulated and found to be sufficient. The printed concrete boxes will be used as column mold; thus, C30 concrete will be casted within the 3D printed shutter frame. Figure 6 presents cross-sections of the enhanced 3D printed model with the capacity of the rooms.

The shelter is made of two rooms and a kitchen. The bathroom is eliminated from the design of this shelter to avoid hygiene problems as well as to fulfil the common requirements of communal bathrooms of the sphere book (The Sphere Project, 2011). The printed walls and foundation will reduce the time of shuttering; thus, the material required to form from traditional concrete will be no longer be required in such printing mechanism. The roof is made of sandwich panels fixed to steel tubes that is welded to base plates and anchored 
to the concrete columns. The sandwich panels will be terminated by aluminium flashing from the outer side of the shelter to eliminate the water from penetrating the shelter. The roofing system simulated through insight 360 has penetrated only $140 \mathrm{kwh} / \mathrm{m}^{2}$ of the solar radiation, achieving higher insulation values to one required in the literature review. The internal doors are made of timber to enhance thermal insulation between the rooms. The windows are made of unplasticised polyvinyl chloride (UPVC) frame with double glazed units to reduce heat flow toward the shelter as well as empower the sound insulation of the UPVC windows by framing a double glazing unit that achieves up to $35 \mathrm{~dB}$ (Glass, 2017). The shelter achieved zero lux over the night and 5,382 lux during the day. Figure 7 presents the simulated light accessibility toward the shelter.

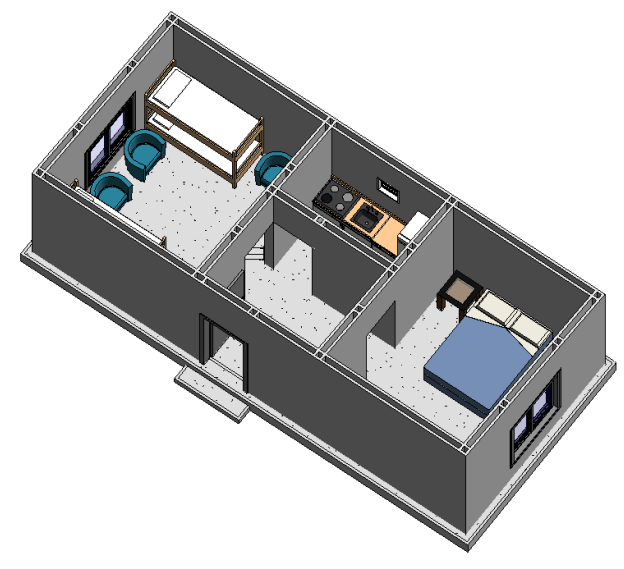

Figure 6. 3D printed shelter cross section
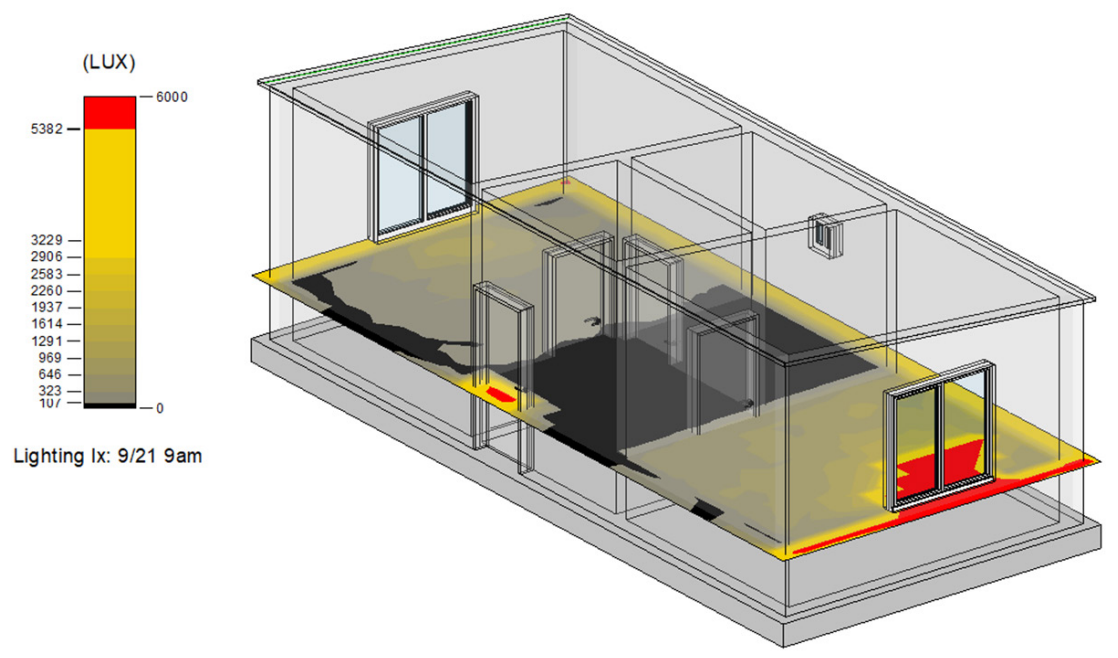

Figure 7. 3D printed shelter lighting model 
The main entrance metal door is flashed on the inner pan of the frame to promote the thermal break combination between the printed wall and the door. The $46 \mathrm{~m}^{2}$ shelter can accommodate up to 10 refugees in which parents with small child in one room and the other ones can accommodate the other children. Figures 8 and 9 present room separation and capacity, as well as the overall perspective of the 3D printed shelter.

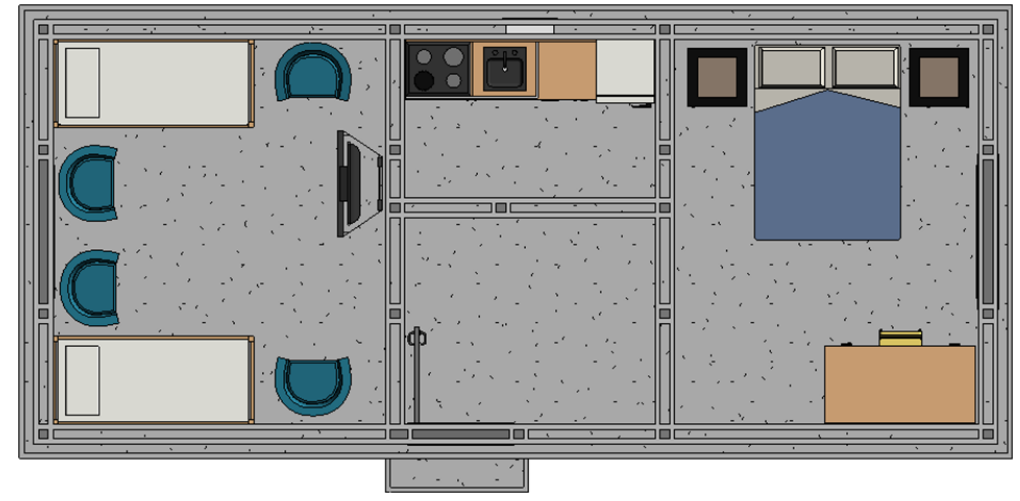

Figure 8. Plan view of 3D printed shelter

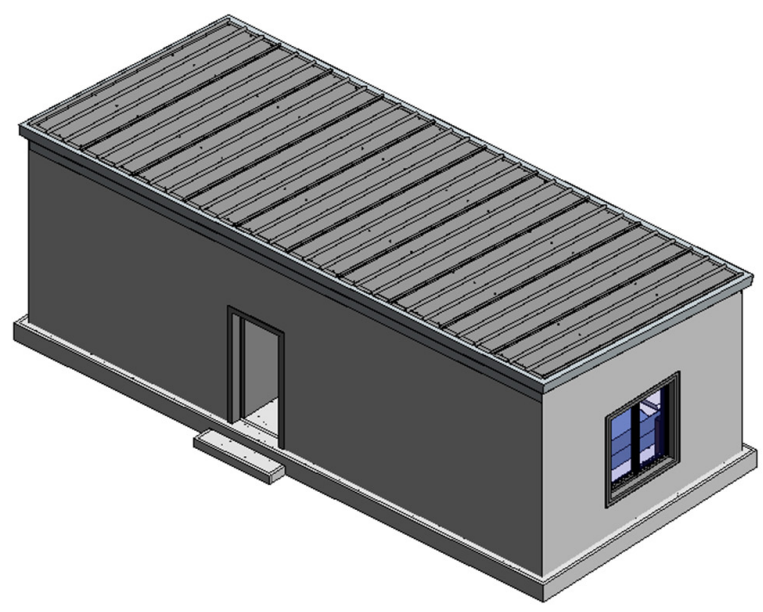

Figure 9. Overall 3D printed shelter perspective

\section{Modifications on Transitional Steel Shelter Model}

The purpose of this section is to modify the dimensions of the steel transitional shelter designed by UNHCR to meet the 3D printed enhanced model dimensions. This is needed to compare the environmental performance of the shelters on the same sizes to ensure the energy consumption levels, the lighting accessibility and the ventilation level controlled from the same measurement aspects. Figure 10 
presents the interlock steel structure matching the size of the concrete printed shelter and Figure 11 presents the cladded steel frame with aluminium insulation foam and double layer of IBR sheets. Figure 12 presents the overall transitional steel shelter matching the printed shelter perspective. The steel shelter achieved $280 \mathrm{kWh} / \mathrm{m}^{2}$ solar insulation per year and the single glazing pan achieved $25 \mathrm{~dB}$ acoustic insulation (Magnetite, 2020) and allowed up to 4,036 lux artificial light during the day and 2 lux during the night as shown in Figure 13.

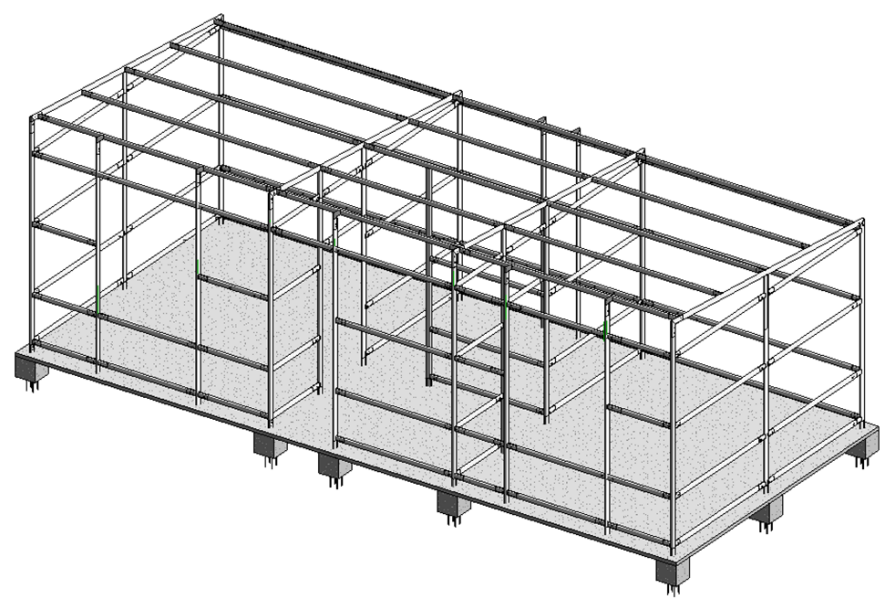

Figure 10. Interlock structural steel framing

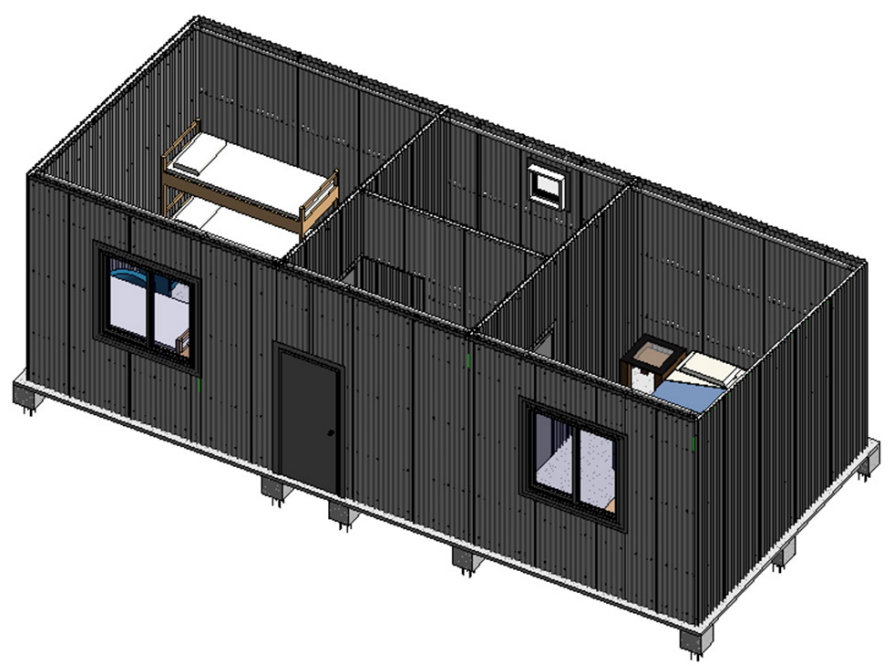

Figure 11. IBR cladding the structural steel frame 


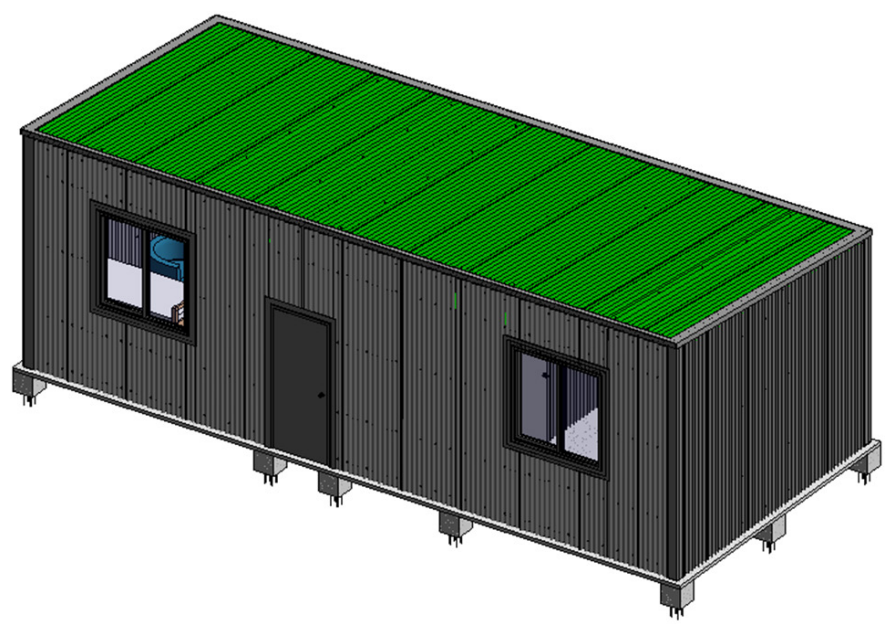

Figure 12. Transitional steel shelter

(LUX)

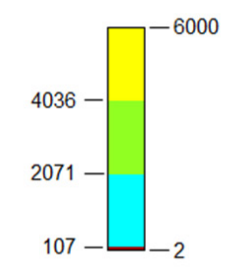

Lighting Ix: 9/21 9am

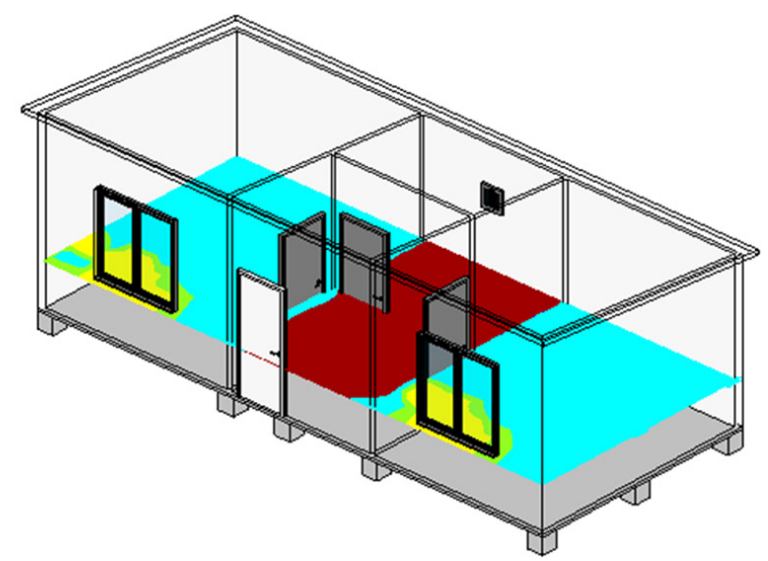

Figure 13. Steel shelter lighting model

\section{Environmental Performance Comparisons}

Revit is one of the BIM groups of software's that enable the power of energy analysis in association with green building studio and provides insight through analysing the thermal, energy and ventilation levels. The thermal performance of building envelope depends on heat transfer coefficient value that is selected from the energy setting of the design model. The following heat transfer coefficient selected for each of the shelter components such as foundations, walls, roof, doors and windows. The heat transfer coefficient selected was based on the closest options the software offers. The complexity of the designed models made the software unable to read the individual performances of building elements and therefore, simpler models created with same materials properties of the original models, 
however with simpler format, in order to run the energy simulation on both of the shelters. Figures 14 and 15 present the selection of the heat transfer coefficient selected in Revit to match the building envelope specification.

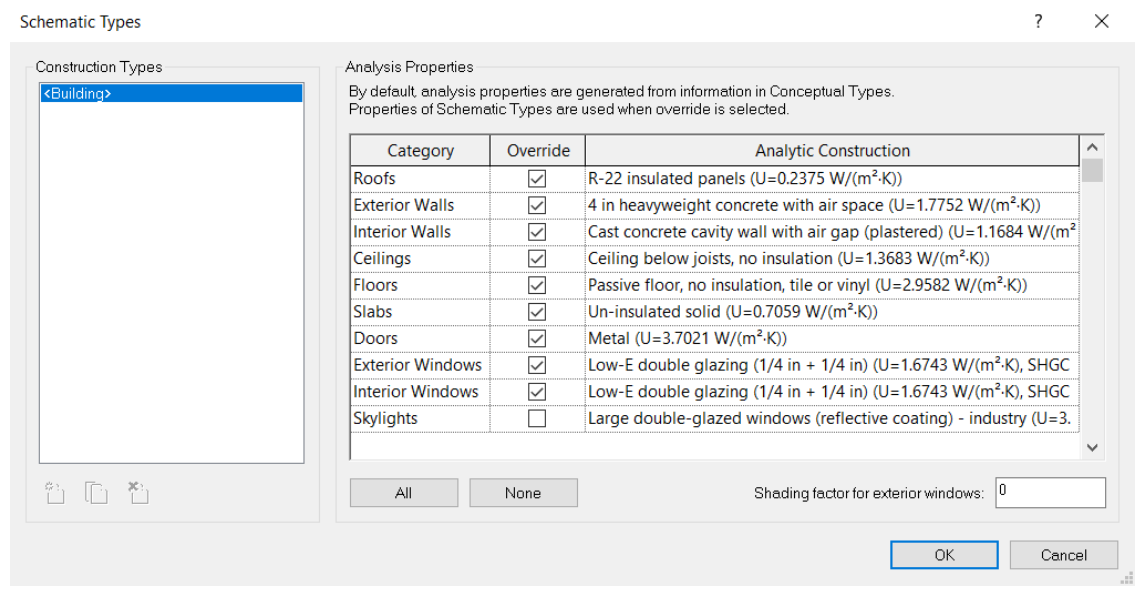

Figure 14. 3D printed shelter energy settings

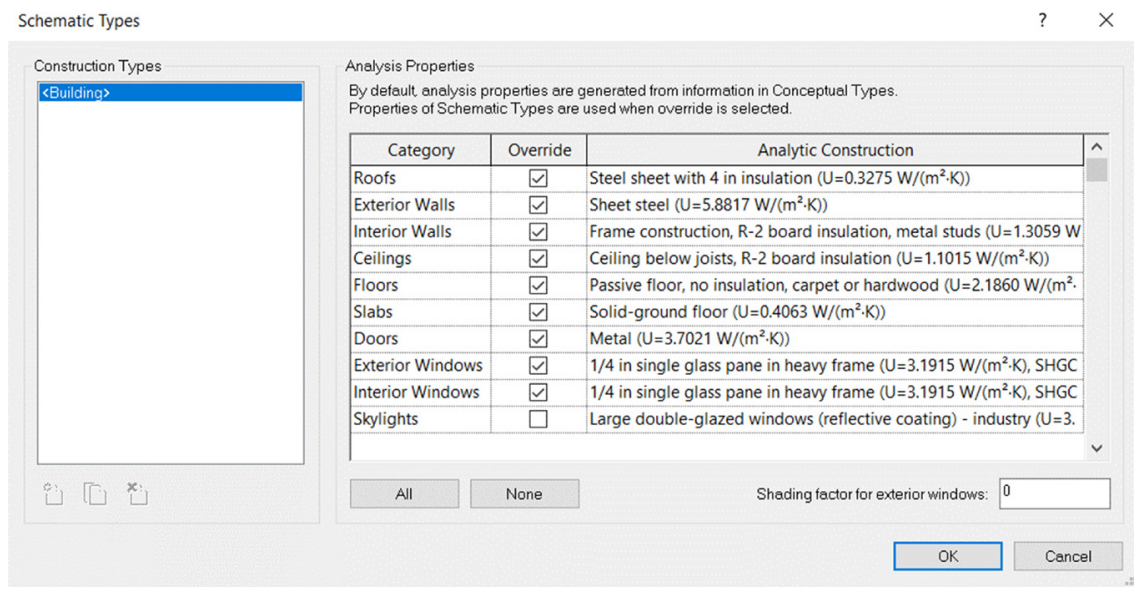

Figure 15. Steel shelter energy settings

Table 1 and Figure 16 summarise the heat coefficient transfer of each of the shelters achieved from the simulation, to compare the performance of one to other on each of the shelter main components. The efficiency formula for representing the difference between 3D printed shelter to steel ones is calculated on improvement formula that, correlates the performance among the two in measured unit, thus the efficiency of thermal insulation calculated by $\left(U_{3 D}-U_{5}\right) / U_{3 D}$ where $U_{3 D}$ is the heat coefficient of building element of 3D printed shelter while $U_{s}$ is the heat coefficient of building element of steel shelter. 
Table 1. Thermal performance of steel and 3D printed shelter

\begin{tabular}{lccc}
\hline $\begin{array}{l}\text { Heat Transfer Coefficient, } \\
U(W / \mathrm{m} 2 \mathrm{~K})=1 / \text { Thermal } \\
\text { Resistance, } R(\mathrm{~m} 2 \mathrm{~K} / \mathrm{W})\end{array}$ & $\begin{array}{c}\text { Steel Shelter } \\
\left(U_{s}\right)\end{array}$ & $\begin{array}{c}\text { 3D Printed Shelter } \\
\left(\boldsymbol{U}_{3 \mathrm{D}}\right)\end{array}$ & $\begin{array}{c}\text { Efficiency of 3D } \\
\text { Printed Shelter to } \\
\text { Steel Shelter }\end{array}$ \\
\hline Foundation & 1.61 & 1.83 & $-14 \%$ \\
Walls & 3.5938 & 1.4718 & $59 \%$ \\
Roof & 1.186 & 0.8029 & $32 \%$ \\
Windows glazing & 3.1915 & 1.6743 & $47 \%$ \\
Entrance door & 3.7021 & 3.7021 & $0 \%$ \\
\hline
\end{tabular}

Thermal Efficiency of 3D Printed Shelter to Steel Shelter

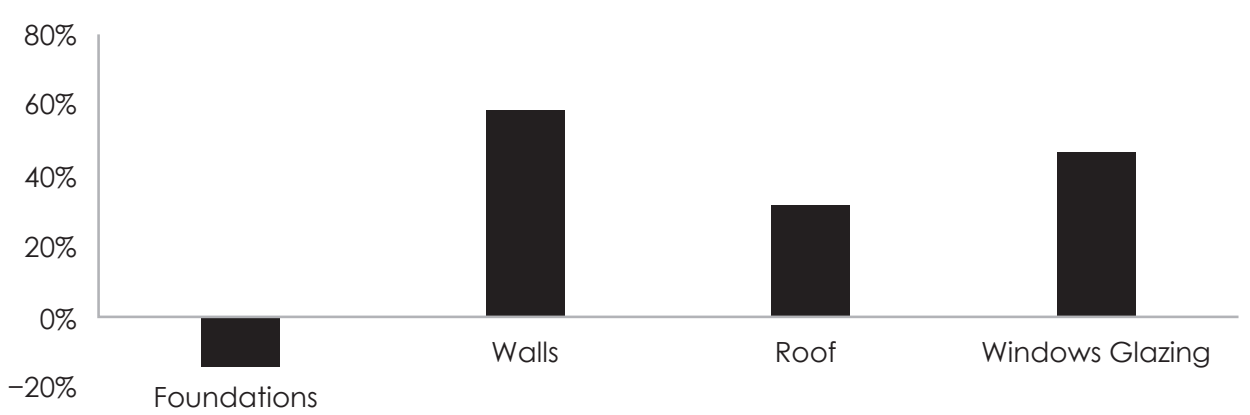

Measured Efficiency Percentage

Figure 16. The Efficiency of 3D Printed Shelter Thermal Performance

As Figure 16 showed the foundation thermal performance of the steel shelter is better than the 3D printed shelter even though both of the foundations are made of concrete. However, the thickness of the concrete played major role in the thermal performance as thicker the slab the weaker it will be in insulating surface above it. The walls of the 3D printed shelter however performs much better thermally than the steel walls as the $10 \mathrm{~cm}$ air gap between the two walls perform as thermal break. The $50 \mathrm{~mm}$ sandwich panel on the printed shelter roof exceeded the performance of the double layer with aluminium foam installed on the steel shelter by $80 \%$. The UPVC window reduces the heat suction through the windows on the printed shelter better than the steel shelter. Finally, since the main entrance doors were made of steel in both the shelters the performance remains the same and thus none of the shelters perform better than the other. All in all, the printed shelter absorbs much lower value of heat on most of the building elements and therefore considered better than the steel in providing the occupants with thermal comfort required during residency. The following table presents the value generated from the simulation of the models in the cloud based BIM tools in order to compare in the form of chart between the two shelters and define the efficiencies of one to another. 
Table 2. Energy, carbon and cost comparison between 3D printed shelter and steel shelter

\begin{tabular}{|c|c|c|c|}
\hline $\begin{array}{l}\text { Energy, Carbon and } \\
\text { Cost Summary }\end{array}$ & Steel Shelter & 3D Printed Shelter & $\begin{array}{l}\text { Efficiency of 3D } \\
\text { Printed Shelter } \\
\text { to Steel Shelter }\end{array}$ \\
\hline Annual energy cost & USD1,709 & USD1,351 & $21 \%$ \\
\hline Lifecycle cost & USD23,278 & USD18,398 & $21 \%$ \\
\hline \multicolumn{4}{|l|}{ Annual $\mathrm{CO}^{2}$ Emissions } \\
\hline Onsite fuel & $5.6 \mathrm{Mg}$ & $4 \mathrm{Mg}$ & $29 \%$ \\
\hline Large SUV equivalent & 0.6 SUVs per year & 0.4 SUVs per year & $33 \%$ \\
\hline \multicolumn{4}{|l|}{ Annual Energy } \\
\hline Energy use intensity (EUI) & $\begin{array}{l}3,834 \mathrm{MJ} / \mathrm{m}^{2} \\
\text { per year }\end{array}$ & $\begin{array}{l}2,742 \mathrm{MJ} / \mathrm{m}^{2} \\
\text { per year }\end{array}$ & $28 \%$ \\
\hline Electric & $11,306 \mathrm{kWh}$ & $9,028 \mathrm{kWh}$ & $20 \%$ \\
\hline Fuel & $113,288 \mathrm{MJ}$ & $80,346 \mathrm{MJ}$ & $29 \%$ \\
\hline Annual peak demand & $3.0 \mathrm{~kW}$ & $2.4 \mathrm{~kW}$ & $19 \%$ \\
\hline \multicolumn{4}{|l|}{ Lifecycle Energy } \\
\hline Electric & $339,172 \mathrm{~kW}$ & $270,838 \mathrm{~kW}$ & $21 \%$ \\
\hline Fuel & $3,398,649 \mathrm{MJ}$ & $2,41,0381 \mathrm{MJ}$ & $29 \%$ \\
\hline \multicolumn{4}{|l|}{ Natural Ventilation Potential } \\
\hline $\begin{array}{l}\text { Total hours mechanical } \\
\text { cooling required }\end{array}$ & $5,466 \mathrm{~h}$ & $5,558 \mathrm{~h}$ & $-2 \%$ \\
\hline $\begin{array}{l}\text { Possible natural ventilation } \\
\text { hours }\end{array}$ & $866 \mathrm{~h}$ & $1,704 \mathrm{~h}$ & $49 \%$ \\
\hline $\begin{array}{l}\text { Possible annual electric } \\
\text { energy savings }\end{array}$ & $1,584 \mathrm{kWh}$ & $1,848 \mathrm{kWh}$ & $14 \%$ \\
\hline $\begin{array}{l}\text { Possible annual electric } \\
\text { cost savings }\end{array}$ & USD218 & USD254 & $14 \%$ \\
\hline $\begin{array}{l}\text { Net hours mechanical } \\
\text { cooling required }\end{array}$ & $4,600 \mathrm{~h}$ & $3,854 \mathrm{~h}$ & $16 \%$ \\
\hline
\end{tabular}

The energy analysis of printed shelter to the steel presented in Figure 17 show that the printed shelter annual expenses to energy is less than the steel shelter by $21 \%$. The annual carbon emission produced by vehicles delivering the steel shelter materials found to be higher than the printed shelter by $33 \%$. The printed shelter achieved $29 \%$ efficiency on site fuel conservations over the other shelter. The amount of electricity consumed by the printed shelter found to be lower than the steel shelter on all measured aspects, for example the printable shelter achieved $28 \%$ in EUI, $20 \%$ in electricity, $29 \%$ in fuel and $19 \%$ on peak energy demand. The printed shelter falls weaker than the steel shelter in the mechanical cooling required to reduce the internal temperature of the shelter. The printed 
shelter however out weights the steel shelter in possible ventilation hours and annual energy saving which make it the ultimate environmental friendly solution in Jordan.

\section{Efficiency of 3D Printed Shelter to Steel Shelter}

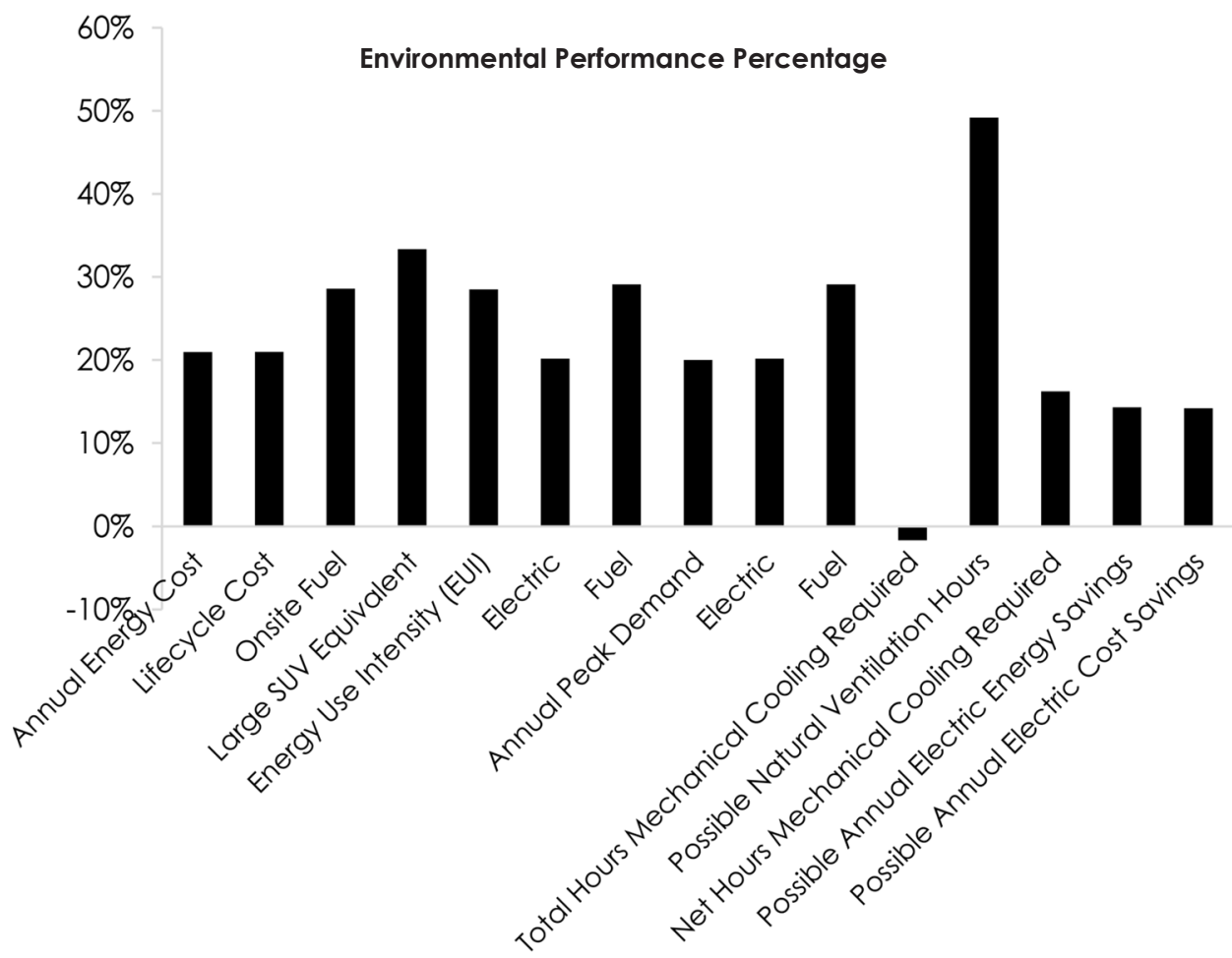

Figure 17. Efficiency of 3D printed shelter to steel shelter

\section{CONCLUSION}

The numbers of Middle East refugees are increasing so significantly over the last decades due to the conflicts in Iraq, Syria, Sudan and Palestine. Syrian refugees located in Jordan over past nine years have been placed in camps during the course of conflicts. The poor sheltering solution provided by the Jordanian government and the United Nation to Syrian refugees, made the research on alternative sheltering solution an extensive area contributing to the knowledge. This article has developed a design model of printable shelter using concrete material and compared it to steel shelter that match to the ones made in Jordanian camps. However, in dimension it matches the concrete printed shelter. The models is then simulated through Green Building Studio and Insight to define the thermal insulation levels, energy consumption amount, ventilation cycles and acoustic performance of the shelters. The results show that, the printed concrete 
shelter performs better in most of the aspects and therefore, can save energy, reduce electricity consumptions, enhance aid follow ability within the shelter and reduce the amount of external noise.

\section{DATA AVAILABILITY}

Access to data is restricted as the research presented in the article is a part of a PhD research that is funded by Swinburne University of Technology, Australia. The models of the research as well as the analytical theme remain under the custody of the university database till the project is completed. Any use of data should be communicated with the authors of the article to ensure no violation to the university copyright of the research.

\section{ACKNOWLEDGEMENTS}

We would like to thank CAD International, Australia for the technical support provided to connect the designed models to the cloud based energy simulation platforms in order to run the analysis and record the results.

\section{REFERENCES}

Aburamadan, R.F. (2017). Developing user-informed specifications for refugee shelters in hot-dry climates: A study of the Al Za'atari camp in Jordan. PhD diss. University of Salford.

Akeila, M., Kuok, K.K.K. and Wong, N.H.M. (2019). Evaluating the visibility of building Syrian refugee shelters by 3D printing technology in Jordan. International Journal of Engineering and Technology, 8(3): 377-385. https://doi.org/10 .14419/ijet.v8i3.29719.

Autodesk (2016). Insight 360 Getting Started Guide. San Rafael, CA: Autodesk Inc. Available at: https://microsolresources.com/wp-content/uploads/2016/10/ Insight-360-Getting-Started-Guide.pdf.

. (2011). Autodesk ${ }^{\circledR}$ Ecotect ${ }^{T M}$ Analysis 2011 : Getting Started with Autodesk Green Building Studio. San Rafael, CA: Autodesk Inc.

Département TI (2007). Acoustic Insulation of Floors, Walls and Ceilings. Canada: Département TI.

Duell, R., Hathorn, T. and Hathorn, T.R. (2015). Autodesk Revit Architecture 2016: Essentials. Indianapolis, IN: John Wiley \& Sons, Inc.

Dupin, V. (2018). Impacts of Electricity Participatory Impact Assessment of Electricity. Jordan: The UN Refugee Agency, Technical Unit, UNHCR Jordan.

Fanger, P.O. (1988). Introduction of the olf and the decipol units to quantify air pollution perceived by humans indoors and outdoors. Energy and Buildings, 12(1): 1-6.

Field Ready (2014). FieldReady: Humanitarian supplies made-in-the-field. About us. Available at: https://www.fieldready.org/about-us [Accessed on 13 July 2018]. 
Fuchs, M., Hegger, M. and Stark, T. (2013). Energy Manual: Sustainable Architecture. Basel, Switzerland: Birkhäuser.

Glass, J. (2017). UPVC Specifications and Standards. Mahasamund, India: JK Glass Works Pt. Ltd.

Hegger, M., Hartwig, J., Keller, M., Reichel, A. and Schultz, K. (2012). Scale: Heat/ Cool: Energy Concepts, Principles, Installations. Basel, Switzerland: Birkhäuser.

Magnetite (2020). Noise reduction technical data and results, 2020. Available at: https://www.magnetite.com.au/magnetite-windows-benefits.html [Accessed on 7 October 2020].

Richarz, C. and Schulz, C. (2013). Energy efficiency refurbishments. Munich: Redaktion DETAIL. https://doi.org/10.11129/detail.9783955531430.

Ritchie, A. and Thomas, R. (2013). Sustainable Urban Design: An Environmental Approach. 2nd Ed. New York: Max Fordham LLP.

The Sphere Project (2011). The Sphere Project: Humanitarian Charter and Minimum Standards in Humanitarian Response. 3rd Ed. Geneva: The Sphere Project. Available at: https://www.unhcr.org/uk/50b491b09.pdf.

UNHCR (United Nations High Commissioner for Refugees) (2018). UNHCR: Figures at a glance. Available at: https://www.unhcr.org/figures-at-a-glance.html [Accessed on 20 January 2019].

. (2016). Shelter Design Catalogue. Geneva: UNHCR Shelter and Settlement Section. Available at: https://cms.emergency.unhcr.org/documents/11982/ 57181/Shelter+Design+Catalogue+January+2016/a891 fdb2-4ef9-42d9-bf0f -c12002b3652e [Accessed on 20 May 2019].

. (2015). Transitional Shelter T shape Design for Azraq Camp. Geneva: UNCHR.

UNHCR Greece (2017). What is the Greece cash alliance? Available at: https:// www.unhcr.org/5al4306a7.pdf.

Weather Spark (2019). Average weather in Mafraq, Jordan, year round. Available at: https://weatherspark.com/y/99599/Average-Weather-in-Mafraq-JordanYear-Round [Accessed on 7 May 2019].

Wikipedia (2018). Decipol. Available at: https://en.wikipedia.org/wiki/Decipol.

WorldData.info (2019). Climate in Aqaba, Jordan. Available at: https://www. worlddata.info/asia/jordan/climate-aqaba.php [Accessed on 7 May 2019]. 